\title{
Regulation of TRP Channels by Phosphorylation
}

\author{
Xiaoqiang Yao Hiu-Yee Kwan Yu Huang \\ Department of Physiology, Faculty of Medicine, The Chinese University of Hong Kong, Hong Kong, SAR, China
}

\author{
Key Words \\ TRP channels $\cdot$ Phosphorylation $\cdot \mathrm{Ca}^{2+}$ influx
}

\begin{abstract}
The transient receptor potential (TRP) channels are a group of $\mathrm{Ca}^{2+}$-permeable cation channels (except TRPM4 and TRPM5) that function as cellular sensors of various internal and external stimuli. Most of these channels are expressed in the nervous system and they play a key role in sensory physiology. They may respond to temperature, pressure, inflammatory agents, pain, osmolarity, taste and many other stimuli. Recent development indicates that the activity of these channels is regulated by protein phosphorylation and dephosphorylation of serine, threonine, and tyrosine residues. In this review, we present a comprehensive summary of the literature regarding the TRP channel regulation by different protein kinases.
\end{abstract}

Copyright $\Subset 2005$ S. Karger AG, Basel

\section{Introduction}

Transient receptor potential (TRP) channels were first cloned in Drosophila melanogaster. Tremendous advances in recent years have resulted in the isolation of approximately 30 unique TRP homologs [1, 2]. These homologs have been divided into seven subfamilies: canonical TRPC, vanilloid TRPV, melastatin TRPM, poly- cystin TRPP, mucolipin TRPML, ankyrin transmembrane proteins (TRPA) and NOMPC-like TRPN [1, 2]. TRP channels are $\mathrm{Ca}^{2+}$-permeable (except for TRPM4 and TRPM5) cation channels composed of four subunits. With the exception of some polycystins, all TRP subunits possess six transmembrane segments. TRPC, TRPV, and TRPA channels contain ankyrin repeats at their N-terminal cytoplasmic domains. These ankyrin repeats are thought to play key roles in protein-protein interactions $[1,3]$. In addition, TRPC and TRPM both contain proline-rich domains in the region just C-terminal to the sixth transmembrane segment.

The importance of TRP channels in the nervous systems has been well documented [2, 4]. TRP channels serve as sensors to perceive and respond to environmental stimuli including temperature, taste, mechanical forces, pain and pheromones [2, 4], and then transform various environmental stimuli into changes in cytosolic $\mathrm{Ca}^{2+}$ levels and/or membrane potentials in peripheral neurons. In the central nervous system, TRP channels may underlie metabotropic glutamate receptor (mGluR)mediated excitatory postsynaptic potentials (EPSPs) [5, 6]. Recent evidence indicates that TRP channels are crucial for the guidance of nerve growth cones in the developing nervous system $[7,8]$.

There is a high degree of diversity in the modes of activation and regulation of TRP channels. Physical (e.g., temperature and mechanical forces) and chemical (e.g., hormones, neurotransmitters and growth factors) stimuli activate different TRP channels via diverse mechanisms

\section{KARGER}

Fax +4161306 1234 E-Mail karger@karger.ch www.karger.com
C 2005 S. Karger AG, Basel

$1424-862 X / 05 / 0146-0273 \$ 22.00 / 0$

Accessible online at:

www.karger.com/nsg
Xiaoqiang Yao, $\mathrm{PhD}$

Department of Physiology, Faculty of Medicine

The Chinese University of Hong Kong

Hong Kong, SAR (China)

Tel. +852 2609 6877, Fax +852 2603 5022, E-Mail yao2068@cuhk.edu.hk 
including alteration of cellular diacylglycerol (DAG) levels, changes in cytosolic $\mathrm{Ca}^{2+}$ levels, depletion of $\mathrm{Ca}^{2+}$ stores, changes in protein phosphorylation, and variations in protein-protein interactions that occur either between different TRP isoforms or when TRP channel proteins interact with other unique proteins. Most of these topics have been extensively discussed in previous reviews $[1,3,9,10]$ and will not be further discussed here. The focus of this review will be on the regulation of TRP channel activity by protein phosphorylation.

Protein phosphorylation and dephosphorylation are common, reversible, posttranslational modifications that can regulate the structure and function of ion channels. A particular phosphorylation/dephosphorylation state can modify channel activity and thus alter the electrophysiological properties of excitable and non-excitable cells. A few well-known examples include protein kinase $\mathrm{G}(\mathrm{PKG})$ regulation of large conductance $\mathrm{Ca}^{2+}$-dependent $\mathrm{K}^{+}$channels $\left(\mathrm{BK}_{\mathrm{Ca}}\right)$ and the regulation of NMDA receptors by tyrosine phosphorylation. The $\mathrm{BK}_{\mathrm{Ca}}$ channel is composed of four $\alpha$-subunits that form the pore and a regulatory $\beta$-subunit; the channel is regulated by voltage in a $\mathrm{Ca}^{2+}$-dependent manner. PKG phosphorylates the $\alpha$-subunit at Ser-1072 near the C-terminus, shifting the $\mathrm{Ca}^{2+}$ sensitivity of the channel and producing hyperpolarization [11]. NMDA receptors are regulated in part by the opposing actions of protein tyrosine kinases and phosphotyrosine phosphatases. Src phosphorylates the NMDA receptor subunits and/or other proteins in the NMDA receptor complex, resulting in enhanced single-channel gating of NMDA receptors and as a consequence increases the NMDA receptor-mediated synaptic currents in neurons [12]. In last few years, rapid development in the field of TRP channel research has demonstrated an important role for protein phosphorylation in the regulation of TRP channels, particularly for the members of the TRPC, TRPV, TRPM, and TRPP subfamilies.

\section{TRPC Channels}

The TRPC subfamily contains seven members, which can be further divided into four subgroups: TRPC1, TRPC2, TRPC4,5, and TRPC3,6,7 [1, 3]. TRPC1 needs to form heteromultimeric complex with TRPC4 or TRPC 5 for its proper trafficking to plasma membrane to form functional channels [6]. TRPC2 participates in pheromone sensory signaling and sperm fertilization [1], but in humans, TRPC2 is a pseudogene [1, 3]. TRPC 3, 6 and 7 form a subfamily sharing amino acids identities between 70 and $80 \%$, whereas TRPC4 and 5 form another subgroup with unique characteristics of potentiation by lanthanides. Lanthanides are among the most commonly used inhibitors for non-selective cation channels. Surprisingly, they activate TRPC4, TRPC5, and the heteromer of TRPC1 and TRPC5 [1, 6]. TRPC channels are widely expressed in the nervous systems including the cortex, thalamus, hippocampus, cerebellum, brainstem, spinal cord and peripheral ganglia $[6,7,13]$. Functionally, TRPC1 and TRPC5 are believed to form the molecular basis of group $1 \mathrm{mGluR}$-activated cation channels $[5,6]$, whereas TRPC4 may influence the GABA release from dendrites of thalamic interneurons [14]. Furthermore, TRPC1, 3, 5, and 6 play crucial roles in the guidance of neuronal growth cones, including those in hippocampal neurons, cerebellar granule neurons, and spinal neurons $[7,8]$.

TRPC channels are activated by agonist- or growth factor-mediated stimulation of phospholipase C- $\beta$ (PLC- $\beta$ ) and PLC- $\gamma[1,3]$. Activation following PLC stimulation appears to be via diverse pathways. The activity of PLC generates inositol 1,4,5-trisphosphate ( $\left.\mathrm{IP}_{3}\right)$, which may induce $\mathrm{IP}_{3}$ receptor-mediated $\mathrm{Ca}^{2+}$ release from intracellular $\mathrm{Ca}^{2+}$ stores. The resultant decrease in store $\mathrm{Ca}^{2+}$ content activates most TRPC channels via a capacitative mechanism under certain conditions [1,9]. PLC activity also produces DAG, which activates TRPC3, 6, and 7, independent of $\mathrm{Ca}^{2+}$ store depletion $[1,3]$. Regarding the regulation by phosphorylation, protein kinase $\mathrm{C}$ (PKC) and PKG both inhibit TRPC channels, except for TRPC1, which is activated by PKC. On the other hand, CaM-kinase II activates TRPC6; Src family non-receptor tyrosine kinases activate both TRPC3 and TRPC6 (table 1).

\section{Phosphorylation of TRPC by PKC and PKG}

Zhang and Saffen [15] provided the first evidence that TRPC6 activity is negatively regulated by PKC. They found that TRPC6, when overexpressed in CHO cells, was inhibited by phorbol 12-myristate 13-acetate (PMA), which activates PKC, and furthermore, the PMAinduced inhibition was abolished in the presence of GF109203X, a highly selective and potent inhibitor of multiple PKC subtypes. Similar studies by two other groups found that TRPC 3, 4 and 5 were also inhibited by PKC in HEK293 or DT40 overexpression system [16]. Recently, Trebak et al. [17] identified Ser-712 in the TRPC3 amino acid sequences to be a specific PKC phosphorylation site. A point mutation at this site abolished the PKC phosphorylation on TRPC3 proteins and also markedly reduced the inhibitory effect of PKC on TRPC3- 
Table 1. Phosphorylation regulation of TRPC channels

\begin{tabular}{lll}
\hline Gene name & Mode of activation & Phosphorylation and action \\
\hline TRPC1 & Capacitative, membrane stretch & PKC activates [24] \\
TRPC3 & Capacitative, DAG & PKC and PKG inhibit [15-17, 20] \\
& & Src activates [26] \\
TRPC4 & Capacitative & PKC inhibits [16] \\
TRPC5 & Capacitative? & PKC inhibits [16] \\
TRPC6 & Capacitative? DAG & PKC and PKG? inhibit $[15,16,20]$ \\
& & Fyn and CaMKII activate $[19,25]$ \\
TRPC7 & Capacitative, DAG & PKC and PKG? inhibit $[16,20]$ \\
\hline
\end{tabular}

mediated $\mathrm{Ca}^{2+}$ influx. Ser-712 is located within a consensus PKC phosphorylation sequence of - $\mathrm{PS}^{712} \mathrm{PKS}$-, which is conserved between two TRPC subfamilies, TRPC 3,6,7 and TRP4,5, suggesting that the same site may be responsible for PKC-induced inhibition of TRPC4, 5, 6 and 7. Another study by Zhu et al. [18] found that PKC phosphorylates Thr-972 of mouse TRPC5, causing channel desensitization. Thr-972 resides in a $\mathrm{VT}^{972} \mathrm{TRL}$ motif that interacts with PDZ domains. It is possible that PKC phosphorylation at Thr-972 may disrupt the interaction of TRPC5 with PDZ domains of other proteins, such as NHERF, resulting in channel desensitization. TRPC6 and 7 are also desensitized by PKC [19]. Channel desensitization is expected to cause an overall reduction in $\mathrm{Ca}^{2+}$ influx. However, several lines of evidence suggest that different mechanisms may govern the channel desensitization observed by Zhu et al. [18] and the overall PKCmediated inhibition of TRPC channels observed by many others [15-17]: (1) Thr-972 is only conserved between TRPC 4 and 5 and therefore, this channel desensitization mechanism cannot apply to TRPC3, 6, and 7; (2) PKCmediated general inhibition of TRPC is due to PKC phosphorylation on -PS ${ }^{712} \mathrm{PKS}$ - [17], but disruption of this PKC site has no effect on channel desensitization [17].

PKG is another kinase capable of inhibiting TRPC3 activity [20]. Our recent studies have shown that the activation of PKG by cyclic GMP (cGMP) inhibits TRPC3mediated $\mathrm{Ca}^{2+}$ influx in TRPC3-overexpressing HEK cells and that this inhibitory effect of cGMP is abolished by the PKG inhibitors KT5823 and H-8. Furthermore, disruption of two consensus PKG phosphorylation sites, Thr-11 and Ser-263, markedly reduces the inhibitory effect of cGMP. These data indicate that PKG phosphorylates TRPC 3 at Thr-11 and Ser-263, and as a consequence, inactivates TRPC3 [20]. A protein sequence alignment shows that two PKG phosphorylation sites in TRPC3, -RRxT ${ }^{11}$ - and -RRKLS ${ }^{263}$ MQC-, are both conserved in TRPC6 and 7, thus suggesting that PKG may also inhibit them. An inhibitory action of PKC and PKG on TRPC may represent important negative feedback mechanisms in the control of cytosolic $\mathrm{Ca}^{2+}$ levels, thereby influencing $\mathrm{Ca}^{2+}$-dependent processes in a variety of different cell types (fig. 1). In these negative feedback pathways, the activation of TRPC results in $\mathrm{Ca}^{2+}$ entry; a rise in cytosolic $\mathrm{Ca}^{2+}$, together with elevated DAG levels, stimulates PKC activity, which feeds back to inactivate the TRPC channels [16] (fig. 1). The elevation of cytosolic $\mathrm{Ca}^{2+}$ also stimulates the activity of nitric oxide synthase (e.g., neuronal nitric oxide synthase), leading to increased production of cGMP. This second messenger activates PKG; the ensuing phosphorylation inhibits TRPC channel activity and completes a PKG-dependent negative feedback loop [20-22] (fig. 1). Recent studies from our group also demonstrated that these two negative feedback loops are connected: PKG is a downstream target of PKC [23]. Importantly, point mutations at two PKG phosphorylation sites (T11A and S263Q) of TRPC3 markedly reduce the PKC inhibition of TRPC3. Furthermore, inhibition of PKG activity by KT5823 (1 $\mu M)$ or H8 $(10 \mu M)$ also greatly reduces PKC inhibition of TRPC3. These data strongly suggest that PKC may also inhibit TRPC channels indirectly by activating PKG. Both PKC- and PKG-mediated negative feedback pathways may play important roles in the regulation of $\mathrm{Ca}^{2+}$ influx in neurons, and may serve to protect neurons from the detrimental effects of excessive $\mathrm{NO}, \mathrm{Ca}^{2+}$ and PKC activation [16, 20-22]. However, the response of TRPC1 to PKC is very different from either TRPC 3,6,7 or TRPC4,5. Contrary to other TRPC channels, TRPC1 is activated by direct PKC phosphorylation [24].

\section{Src and TRPC3, 6}

It has been known for a long time that tyrosine kinases are involved in the activation of capacitative $\mathrm{Ca}^{2+}$ influx [9], of which TRPC channels are among the major molecular candidates $[1,9]$. Two recent studies have pro- 


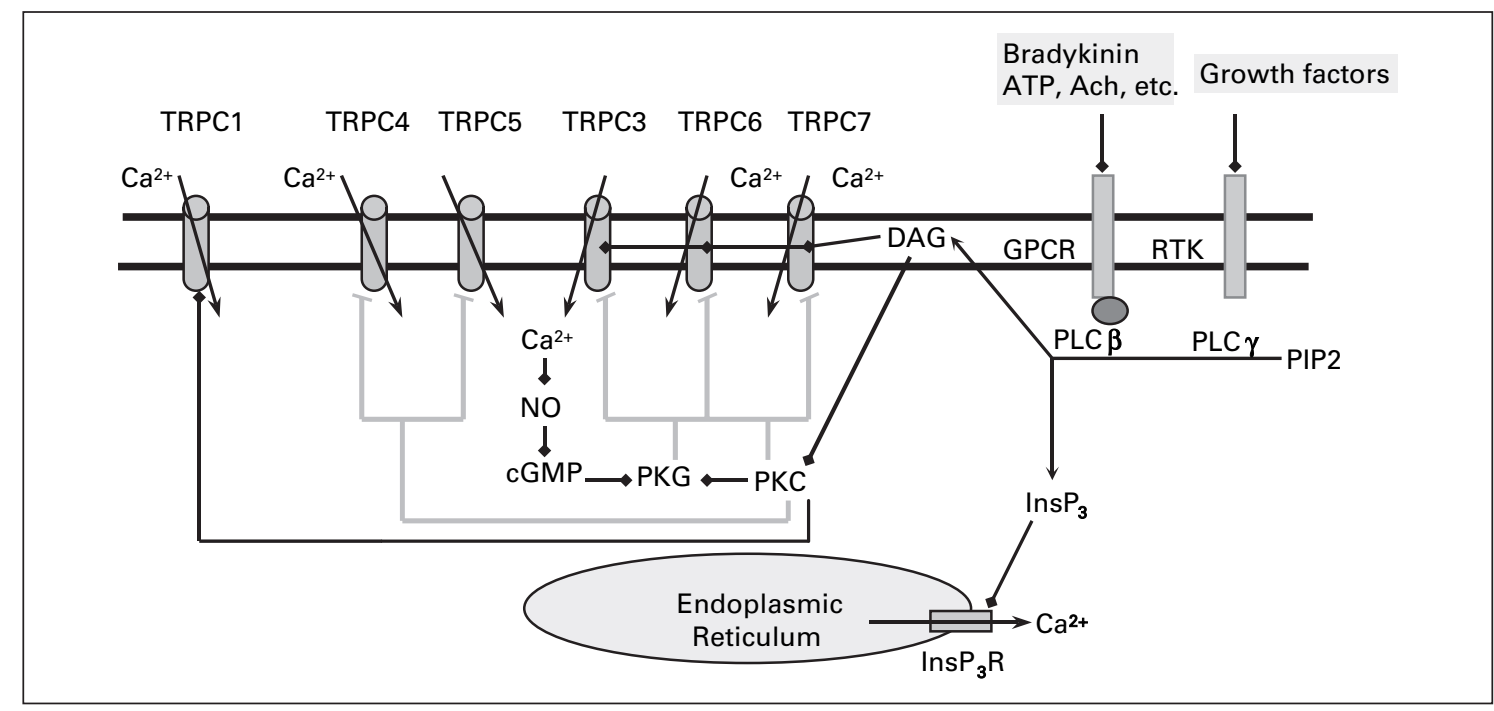

Fig. 1. Activation and PKC- and PKG-mediated regulation of TRPC channels. Agonists bind to either G-proteincoupled receptors (GPCR) or tyrosine kinase-linked receptors (RTK) to activate PLC- $\beta$ or PLC- $\gamma$, leading to the production of diacylglycerol (DAG) and InsP $\mathrm{P}_{3}$. InsP $\mathrm{P}_{3}$ binds to its receptor $\left(\mathrm{Ins} \mathrm{P}_{3} \mathrm{R}\right)$, resulting in store $\mathrm{Ca}^{2+}$ release and activating TRP-mediated capacitative $\mathrm{Ca}^{2+}$ entry. DAG activates some TRP channels such as TRPC3,6,7 via non-capacitative mechanism. DAG also activates PKC, which inhibits TRPC3,4,5,6,7 but stimulates TRPC1. A rise in $\left[\mathrm{Ca}^{2+}\right]_{\mathrm{i}}$ also activates $\mathrm{PKG}$ via NO/cGMP pathway. PKG then inactivates TRPC3,6,7 in a negative feedback mechanism. PKG can also be activated by PKC, leading to the inhibition of TRPC3,6,7. Black symbols $(\longrightarrow)$, stimulatory processes; gray symbols $(-/)$, inhibitory processes.

vided evidence that the Src family of non-receptor tyrosine kinases plays a key role in DAG-induced activation of TRPC3 and TRPC6 [25, 26]. Vazquez et al. [26] found that inhibition of Src kinases by genistein and erbstatin abolished the receptor- and OAG (a DAG analog)-induced activation of TRPC 3. In addition, OAG failed to activate TRPC3 in cells that were either Src-deficient or expressed a dominant-negative mutant of Src, and furthermore, OAG activation of TRPC 3 was restored after the cells were transfected with a Src-expressing construct. These results indicate an obligatory requirement for Src kinase in DAG-induced activation of TRPC3. Note that Src may not directly act on TRPC3. Instead, a concerted role for both DAG and Src seems to be necessary for TRPC3 activation, perhaps through a mechanism involving Src-dependent phosphorylation and/or recruitment of a yet unknown accessory/regulatory protein within the vicinity of TRPC3. In addition to TRPC3, the activation of TRPC6 by DAG may also involve Fyn (a Src family kinase) [25], whose $\mathrm{SH} 2$ domain physically associates with the N-terminal region of TRPC6. The associated Fyn directly phosphorylates TRPC6, and as a consequence, increases the activity of TRPC6 channel [25].

\section{CaM-Kinase II and TRPC6}

CaM-kinase II can activate TRPC6. In patch-clamp studies, Shi et al. [19] found that TRPC6, expressed in HEK293 cells, was activated by extracellular $\mathrm{Ca}^{2+}$, which could be prevented by either an organic CaM-kinase II inhibitor KN-62 or a CaM-kinase II-specific inhibitory peptide. These results suggest that CaM-kinase II-mediated phosphorylation is an obligatory step for TRPC6 channel activation. Surprisingly, the same study also found that inhibitors of CaM-kinase II failed to affect TRPC7, a close relative of TRPC6, suggesting that the regulation by CaM-kinase II may not be a universal mechanism for other TRPC channels.

\section{TRPV Channel}

The TRPV subfamily contains six members (TRPV16). TRPV1-4 channels are temperature-sensitive. Exogenous vanilloids such as capsaisin can activate TRPV1, whereas endogenous lipid signaling molecules such as anandamide and eicosanoid can activate TRPV1 and TRPV4 [27, 28]. TRPV5 and TRPV6 are only distinctly related to TRPV1-4 with a 30-40\% sequence homology. 
Table 2. Phosphorylation regulation of TRPV channels

\begin{tabular}{lll}
\hline Gene name & Mode of activation & Phosphorylation and action \\
\hline TRPV1 & Heat, vanilloids, anandamine, protons & $\begin{array}{l}\text { PKA and PKC sensitize the responses to capsaisin, heat } \\
\text { and anandamide [29-35]. CaMKII is required for activation } \\
\text { by capsaisin [33]. PKA reduces desensitization [36-38] }\end{array}$ \\
TRPV2 & Heat, membrane stretch & PKA potentiates the heat response [40] \\
TRPV4 & Warm, osmotic cell swelling flow shear stress, 5'-6'-EET & PKC activates [41]. Tyrosine kinase activates [42, 43]? \\
TRPV5 & Low intracellular $\mathrm{Ca}^{2+}$, hyperpolarization & SGK1 activates [44] \\
TRPV6 & Low intracellular $\mathrm{Ca}^{2+}$, hyperpolarization & Src activates [46]. PKC reduces inactivation [45] \\
\hline
\end{tabular}

TRPV5 and TRPV6 have high selectivity for $\mathrm{Ca}^{2+}$ over $\mathrm{Na}^{+}\left(\mathrm{P}_{\mathrm{Ca}} / \mathrm{P}_{\mathrm{Na}}>100\right)$, are mainly expressed in $\mathrm{Ca}^{2+}$-transporting epithelia, and are assumed to play an important role in $\mathrm{Ca}^{2+}$ (re)absorption by the kidney and intestine [1]. The activity of many TRPV channels can also be modulated by protein phosphorylation (table 2 ).

\section{Phosphorylation of TRPV1 by PKC, Protein Kinase A} (PKA), and CaM-Kinase II

TRPV1 is a non-selective cation channel expressed predominantly in nociceptive sensory neurons, and the channel is known to play a major role in mediating inflammatory and thermal nociception. Mice lacking TRPV1 display reduced thermal hyperalgesia following inflammation or local injection of bradykinin and nerve growth factor [27]. Multiple kinases are known to regulate TRPV1. PKC phosphorylates Ser-502 and Ser-800 in rat TRPV1, and as a result, either potentiates or sensitizes responses of this channel to capsaisin, heat, and anandamide [29-32]. In addition, CaM-kinase II phosphorylates rat TRPV1 on Ser-502 and Thr-704, and the phosphorylation is required for channel activation by capsaisin [33]. PKA may also phosphorylate TRPV1 on Ser-502, and as a consequence, sensitizes the response of TRPV1 to both heat [34] and capsaicin [35]. Protein phosphorylation may also modulate the desensitization process of TRPV1, thereby affecting adaptation during pain perception. Amino acid residues Thr-370 and Ser116 in rat TRPV1 appear to be particularly important in this regard. PKA can phosphorylate Thr-370 and Ser116 , reducing desensitization. On the other hand, calcineurin can dephosphorylate Thr-370, facilitating desensitization [36-38].

\section{Regulation of TRPV 2 and TRPV4 by Phosphorylation}

TRPV2 and TRPV4 are two temperature-sensitive channels with activation thresholds of $\geq 53$ and $\geq 25$ - $27^{\circ} \mathrm{C}$, respectively [39]. Functionally, TRPV2 is believed to be involved in the sensory response to noxious temperatures, whereas TRPV4 appears to be related to thermosensing, mechanosensing, neuropathic pain, and vascular regulation [28, 39]. TRPV2 is a substrate of PKA. In mast cells, PKA interacts with TRPV2 through a PKAbinding protein named ACBD3 [40]. PKA phosphorylation enhances TRPV2-mediated $\mathrm{Ca}^{2+}$ influx in response to heat [40]. On the other hand, the activity of TRPV4 is stimulated by PKC [41], although it is unclear whether this stimulation is due to direct PKC phosphorylation on TRPV4 proteins. One study suggested that TRPV4 is regulated by tyrosine phosphorylation [42], but this finding has been disputed [43].

\section{Regulation of TRPV5 and 6 by SGK1, PKC and Src}

TRPV 5 is activated by serum and glucocorticoid-inducible kinase, SGK1. This stimulatory effect is due to enhanced TRPV5 abundance in the plasma membrane, requiring the presence of the scaffold protein, NHERF2 [44]. On the other hand, the activity of TRPV6 can be regulated by calmodulin and PKC. Binding of $\mathrm{Ca}^{2+}$-dependent calmodulin to TRPV6 inactivates the channel, which is countered by PKC-mediated phosphorylation of TRPV6 [45]. Thus, by altering the inactivation behavior of TRPV6, PKC-mediated phosphorylation acts as a switch to regulate the amount of $\mathrm{Ca}^{2+}$ influx through TRPV6 [45]. TRPV6 can also be activated by the Src tyrosine kinase, which is counterbalanced by the protein tyrosine phosphatase 1B [46]. Taken together, TRPV6 activity is closely controlled by both the calmodulin/PKC system and the tyrosine kinase/phosphatase system [45, 46]. 
Table 3. Phosphorylation regulation of TRPM and TRPP channels

\begin{tabular}{lll}
\hline Gene name & Mode of activation & Phosphorylation and action \\
\hline TRPM4 & $\mathrm{Ca}^{2+}$-activated, voltage-gated, mechanic pressure & PKC sensitizes the responses to $\mathrm{Ca}^{2+}[48]$ \\
TRPM7 & Oxidative stress, $\mathrm{Mg}^{2+}$-ATP & PKA and Src activate [51, 52] \\
TRPP1 & Flow shear stress, not a channel by itself & Tyrosine kinase inhibits TRPP1 interaction with pp125FAK [59] \\
TRPP2 & $\mathrm{Ca}^{2+}$, protons, complex with TRPP1 & $\begin{array}{l}\text { CK2 sensitizes the responses to Ca }{ }^{2+} \text { and facilitates the retrieval } \\
\text { of TRPP2 into intracellular compartment [61, 62] }\end{array}$ \\
\hline
\end{tabular}

\section{TRPM Channels}

The TRPM subfamily consists of eight members (TRPM1-8). The C-terminal sequences of the TRPM family vary in both length and structure. Three members of the TRPM subfamily (TRPM2, TRPM6 and TRPM7) have enzymatic activity [1]. TRPM2 has a nucleoside diphosphatase domain that binds specifically to and hydrolyzes ADP-ribose, whereas TRPM6 and TRPM7 contain $\alpha$-kinase domains. TRPM channels have more diverse ion selectivities than other TRP channels. TRPM2, TRPM3, and TRPM8 are $\mathrm{Ca}^{2+}$-permeable channels, whereas TRPM4 and TRPM5 are impermeable to $\mathrm{Ca}^{2+}$. TRPM6 and TRPM7 are primarily responsible for $\mathrm{Mg}^{2+}$ transport. Regulation of TRPM by phosphorylation is summarized in table 3.

\section{Phosphorylation of TRPM4 by PKC}

TRPM4 is a voltage-dependent, $\mathrm{Ca}^{2+}$-impermeable cation channel. Opening of this channel depolarizes the membrane. The channel is activated by intracellular $\mathrm{Ca}^{2+}$, but the currents decay rapidly due to decreased sensitivity of the channels to $\mathrm{Ca}^{2+}$. PMA, an activator of PKC, increases the activity of TRPM4 [47] by enhancing the sensitivity of TRPM4 to $\mathrm{Ca}^{2+}$ [48]. Disruption of two PKC phosphorylation sites, Ser-1 145 and Ser-1142, abolishes the PMA-induced activation of human TRPM4, indicating that the channel activation is due to direct PKC phosphorylation on these sites [48].

\section{Regulation of TRPM7 by Src and PKA}

TRPM7 is highly permeable to $\mathrm{Mg}^{2+}[1,49]$, and is therefore crucial for $\mathrm{Mg}^{2+}$ homeostasis. The channel is associated with cell proliferation, cell survival, and anoxic neuronal death $[1,50]$. TRPM7 contains an atypical $\alpha$-kinase domain in its $\mathrm{C}$-terminal region, but the specific function of this kinase is unclear [1]. One possible role for this kinase domain is to mediate the effects of cAMP and PKA, both of which enhance channel activity [51]. Sepa- rately, there is strong evidence that the TRPM7 channel is activated by the Src tyrosine kinase in rat brain microglia [52]. Because Src family tyrosine kinases are coupled to multiple receptor-mediated pathways, it is reasonable to speculate that TRPM7 may allow $\mathrm{Ca}^{2+}$ and $\mathrm{Mg}^{2+}$ entry in response to stimulation by tyrosine kinase-coupled receptor, thereby participating in various cellular responses.

\section{TRPP Channels}

There are four members in the TRPP subfamily, TRPP $1-3$ and TRPP5 [1, 2]. TRPP2, TRPP 3 and TRPP5 share sequence homology with other TRP channel subfamilies and function as $\mathrm{Ca}^{2+}$-permeable cation channels $[1,2]$. The best known TRPP channels are TRPP1 (PKD1) and TRPP2 (PKD2). Mutations in either of these two genes result in autosomal dominant polycystic kidney disease (ADPKD), an inherited disorder that is one of the primary causes of renal failure in humans [53]. TRPP2 and Lov-1 (a homolog of human TRPP1) are expressed in ciliated sensory neurons of Caenorhabditis elegans, and are necessary for male sensory behaviors [54]. There is a general lack of information on the functional roles of TRPP1 and TRPP2 in the mammalian nervous system and many other systems, partly because of the low level of endogenous TRPP1 expression in native cells [55]. Regulation of TRPP by phosphorylation is summarized in table 3 .

\section{Regulation of TRPP1 and 2 by Tyrosine}

Phosphorylation and Casein Kinase 2 (CK2)

TRPP1 is phosphorylated by tyrosine kinase [56, 57] and PKA [57, 58]. Tyrosine phosphorylation facilitates the interaction of TRPP1 with E-cadherin, but inhibits the interaction of TRPP1 with focal adhesion kinase (pp125FAK) [59]. The overall phosphorylation level of TRPP1 is elevated in ADPKD patients, and this over- 
phosphorylation may interfere the interaction of TRPP1 with TRPP2/E-cadherin/ $\beta$-catenin, and cause the depletion of both TRPP1 and E-cadherin from the plasma membrane [60].

For TRPP2, phosphorylation of Ser-812 appears to be particularly important. Cai et al. [61] found that Ser-812 phosphorylation by CK2 significantly increases the $\mathrm{Ca}^{2+}$ sensitivity of TRPP2 channels. Another recent study found that Ser-812 phosphorylation by CK2 and dephosphorylation by protein phosphatase $2 \mathrm{~A}$ directs the trafficking of TRPP2 to distinct subcellular compartments [62]. Phosphorylated TRPP2 binds to either PACS-1 (phosphofurin acidic cluster sorting protein-1) or PACS2. The binding to PACS-2 causes TRPP2 to be retrieved from the intermediate compartment back to the endoplasmic compartment. On the other hand, the binding to PACS1 causes the retrieval of TRPP2 to the Golgi compartment.

\section{Concluding Remarks}

TRP channels are widely expressed in the central and peripheral nervous systems [2, 4, 6, 13, 39]. Protein phosphorylation has been shown to regulate multiple TRP channels with diverse consequences (tables 1-3). In most cases, phosphorylation leads to increased channel activity. For example, PKC phosphorylation increases the activity of TRPC1 [24] and TRPM4 [47, 48]; the non-receptor tyrosine kinase Fyn directly phosphorylates and activates TRPC6 proteins [25]; on the other hand, PKC and PKG inhibit multiple TRPC channels and such inhibition may represent important negative feedback mechanisms for the tight control of cytosolic $\mathrm{Ca}^{2+}$ levels in many cell types.

The physiological significance of the regulation of TRP channels by phosphorylation is fascinating. TRP channels play diverse functional roles, including thermal sensation, nociception, mechanosensing, growth cone guidance, inflammatory responses, membrane potential control and $\mathrm{Mg}^{2+}$ homeostasis. Various kinases and phosphatases may regulate the activities of different TRP channel isoforms, providing enormous control on diverse cellular processes.

\section{Acknowledgement}

The authors thank the Hong Kong Research Grant Council (CUHK4366/04M) for financial support.

\section{References}

1 Montell C: The TRP superfamily of cation channels. Sci STKE 2005;272:re3.

$\checkmark 2$ Moran MM, Xu H, Clapham DE: TRP ion channels in the nervous system. Curr Opin Neurobiol 2004;14:362-369.

-3 Minke B, Cook B: TRP channel proteins and signal transduction. Physiol Rev 2002;82:429472.

-4 Clapham DE: TRP channels as cellular sensors. Nature 2003;426:517-524.

5 Kim SJ, Kim YS, Yuan JP, Petralia RS, Worley PF, Linden DJ: Activation of the TRPC1 cation channel by metabotropic glutamate receptor mGluR1. Nature 2003;426:285-291.

6 Strubing C, Krapivinsky G, Krapivinsky L, Clapham DE: TRPC1 and TRPC5 form a novel cation channel in mammalian brain. Neuron 2001;29:645-655.

7 Li Y, Jia YC, Cui K, Li N, Zheng ZY, Wang YZ, Yuan XB: Essential role of TRPC channels in the guidance of nerve growth cones by brain-derived neurotrophic factor. Nature 2005;434:894-898.

8 Greka A, Navarro B, Oancea E, Duggan A, Clapham DE: TRPC5 is a regulator of hippocampal neurite length and growth cone morphology. Nat Neurosci 2003;6:837-845.
9 Parekh AB, Putney JW Jr: Store depletion and calcium influx. Physiol Rev 2005;85:757810.

10 Zhu M: Multiple roles of calmodulin and other $\mathrm{Ca}^{2+}$-binding proteins in the functional regulation of TRP channels. Pflügers Arch 2005;450 345-354.

11 Fukao M, Mason HS, Britton FC, Kenyon JL, Horowitz B, Keef KD: Cyclic GMP-dependent protein kinase activates cloned $\mathrm{BKCa}$ channels expressed in mammalian cells by direct phosphorylation at serine 1072. J Biol Chem 1999; 274:10927-10935.

12 Salter MW, Kalia LV: Src kinases: A hub for NMDA receptor regulation. Nat Rev Neurosci 2004;5:317-328.

13 Li HS, Xu XZ, Montell C: Activation of a TRPC3-dependent cation current through the neurotrophin BDNF. Neuron 1999;24:261273.

14 Munsch T, Freichel M, Flockerzi V, Pape HC: Contribution of transient receptor potential channels to the control of GABA release from dendrites. Proc Natl Acad Sci USA 2003;100: 16065-16070.
15 Zhang L, Saffen D: Muscarinic acetylcholine receptor regulation of TRP $6 \mathrm{Ca}^{2+}$ channel isoforms. Molecular structures and functional characterization. J Biol Chem 2001:276: 13331-13339.

16 Venkatachalam K, Zheng F, Gill DL: Regulation of canonical transient receptor potential channel function by diacylglycerol and protein kinase C. J Biol Chem 2003;278:2903129040.

17 Trebak M, Hempel N, Wedel BJ, Smyth JT, Bird GSJ, Putney Jr JW: Negative regulation of TRPC 3 channels by protein kinase $\mathrm{C}$-mediated phosphorylation of serine 712. Mol Pharmacol 2005;67:558-563.

18 Zhu MH, Chae M, Kim HJ, Lee YM, Kim MJ, Jin NG, Yang DK, So I, Kim KW: Desensitization of canonical transient receptor potential channel 5 (TRPC5) by protein kinase C. Am J Physiol 2005:289:C591-C600.

19 Shi J, Mori E, Mori Y, Mori M, Li J, Ito Y, Inoue R: Multiple regulation by calcium of murine homologues of transient receptor potential proteins TRPC6 and TRPC7 expressed in HEK293 cells. J Physiol 2004;561:415-432. 
20 Kwan HY, Huang Y, Yao X: Regulation of canonical transient receptor potential isoform 3 (TRPC3) channel by protein kinase G. Proc Natl Acad Sci USA 2004;101:2625-2630.

-21 Yao X, Huang Y: From nitric oxide to endothelial cytosolic $\mathrm{Ca}^{2+}$ : a negative feedback control. Trends Pharmacol Sci 2003;24:263-266.

-22 Kwan HY, Huang Y, Yao X: Store-operated calcium entry in vascular endothelial cells is inhibited by cGMP via a protein kinase G-dependent mechanism. J Biol Chem 2000;275: 6758-6763.

23 Hou Y, Lascola J, Dulin NO, Ye RD, Browning DD: 2003 Activation of cGMP-dependent protein kinase by protein kinase C. J Biol Chem 278:16706-16712.

-24 Ahmmed GU, Mehta D, Vogel S, Holinstat M, Paria BC, Tiruppathi C, Malik AB: Protein kinase $\mathrm{C} \alpha$ phosphorylates the TRPC1 channel and regulates store-operated $\mathrm{Ca}^{2+}$ entry in endothelial cells. J Biol Chem 2004;279:2094120949.

-25 Hisatsune C, Kuroda Y, Nakamura K, Inoue T, Nakamura T, Michikawa T, Mizutani A, Mikoshiba K: Regulation of TRPC6 channel activity by tyrosine phosphorylation. J Biol Chem 2004;279:18887-18894.

26 Vazquez G, Wedel BJ, Kawasaki BT, Bird GS, Putney JW Jr: Obligatory role of Src kinase in the signaling mechanism for TRPC3 cation channels. J Biol Chem 2004;279:4052140528.

-27 Benham CD, Gunthorpe MJ, Davis JB: TRPV channels as temperature sensors. Cell Calcium 2003;33:479-487.

- 28 Nilius B, Vriens J, Prenen J Droogmans G, Voets T: TRPV4 calcium entry channel: a paradigm for gating diversity. Am J Physiol 2004; 286:C195-C205.

-29 Vellani V, Mappleback S, Moriondo A, Davis JB, McNaughton PA: Protein kinase C activation potentiates gating of the vanilloid receptor VR1 by capsaicin, protons, heat and anandamide. J Physiol 2001;534:813-825.

- 30 Bhave G, Hu H, Glauner KS, Zhu W, Wang H, Brasier DJ, Oxford GS, Gereau RW 4th: Protein kinase $\mathrm{C}$ phosphorylation sensitizes but does not activate the capsaicin receptor transient receptor potential vanilloid 1 (TRPV1). Proc Natl Acad Sci USA 2003;100:1248012485.

-31 Premkumar LS, Ahern GP: Induction of vanilloid receptor channel activity by protein kinase C. Nature 2000;408:985-990.

- 32 Numazaki M, Tominaga T, Toyooka H, Tominaga M: Direct phosphorylation of capsaicin receptor VR1 by protein kinase $\mathrm{C} \varepsilon$ and identification of two target serine residues. J Biol Chem 2002;277:13375-13378.

- 33 Jung J, Shin JS, Lee SY, Hwang SW, Koo J, Cho J, Cho H, Oh U: Phosphorylation of vanilloid receptor 1 by $\mathrm{Ca}^{2+} /$ calmodulin-dependent kinase II regulates its vanilloid binding. J Biol Chem 2004:279:7048-7054.

34 Rathee PK, Distler C, Obreja O, Neuhuber W, Wang GK, Wang SY, Nau C, Kress M: PKA/ AKAP/VR-1 module: a common link of Gsmediated signaling to thermal hyperalgesia. $\mathrm{J}$ Neurosci 2002;22:4740-4745.
35 Lopshire JC, Nicol GD: The cAMP transduction cascade mediates the prostaglandin $\mathrm{E}_{2}$ enhancement of the capsaicin-elicited current in rat sensory neurons: whole-cell and singlechannel studies. J Neurosci 1998;18:60816092.

36 Bhave G, Zhu W, Wang H, Hu H, Brasier DJ, Oxford GS, Gereau RW 4th: cAMP-dependent protein kinase regulates desensitization of the capsaicin receptor (VR1) by direct phosphorylation. Neuron 2002;35:721-731.

-37 Mohapatra DP, Nau C: Regulation of $\mathrm{Ca}^{2+}$-dependent desensitization in the vanilloid receptor TRPV1 by calcineurin and cAMP-dependent protein kinase. J Biol Chem 2005;280: 13424-13432.

38 Mohapatra DP, Nau C: Desensitization of capsaicin-activated currents in the vanilloid receptor TRPV1 is decreased by the cyclic AMP-dependent protein kinase pathway. J Biol Chem 2003;278:50080-50090.

-39 Tominaga M, Caterina MJ: Thermosensation and pain. J Neurobiol 2004:61:3-12.

40 Stokes AJ, Shimoda LM, Koblan-Huberson M, Adra CN, Turner H: A TRPV2-PKA signaling module for transduction of physical stimuli in mast cells. J Exp Med 2004;200:137-147.

$41 \mathrm{Xu} F$, Satoh E, Iijima T: Protein kinase C-mediated $\mathrm{Ca}^{2+}$ entry in HEK 293 cells transiently expressing human TRPV4. Br J Pharmacol 2003;140:413-421.

$42 \mathrm{Xu} \mathrm{H}$, Zhao H, Tian W, Yoshida K, Roullet JB, Cohen DM: Regulation of a transient receptor potential (TRP) channel by tyrosine phosphorylation. SRC family kinase-dependent tyrosine phosphorylation of TRPV4 on TYR-253 mediates its response to hypotonic stress. J Biol Chem 2003;278:11520-11527.

-43 Vriens J, Watanabe H, Janssens A, Droogmans G, Voets T, Nilius B: Cell swelling, heat, and chemical agonists use distinct pathways for the activation of the cation channel TRPV4. Proc Natl Acad Sci USA 2004;101:396-401.

44 Embark HM, Setiawan I, Poppendieck S, van de Graaf SF, Boehmer C, Palmada M, Wieder $\mathrm{T}$, Gersberger R, Cohen P, Yun CC, et al: Regulation of the epithelial $\mathrm{Ca}^{2+}$ channel TRPV5 by the NHE regulating factor NHERF2 and the serum and glucocorticoid inducible kinase isoforms SGK1 and SGK3 expressed in Xenopus oocytes. Cell Physiol Biochem 2004;14:203212.

-45 Niemeyer BA, Bergs C, Wissenbach U, Flockerzi V, Trost C: Competitive regulation of CaT-like-mediated $\mathrm{Ca}^{2+}$ entry by protein kinase $\mathrm{C}$ and calmodulin. Proc Natl Acad Sci USA 2001;98:3600-3605.

46 Sternfeld L, Krause E, Schmid A, Anderie I, Latas A, Al-Shaldi H, Kohl A, Evers K, Hofer HW, Schultz I: Tyrosine phosphatase PTP1B interacts with TRPV6 in vivo and plays a role in TRPV6-mediated calcium influx in HEK293 cells. Cell Signal 2005;17:951-960.

47 Guinamard R, Chatelier A, Lenfant J, Bios P: Activation of the $\mathrm{Ca}^{2+}$-activated nonselective cation channel by diacylglycerol analogues in rat cardiomyocytes. J Cardiovasc Electrophysiol 2004;15:342-348.
48 Nilius B, Prenen J, Tang J, Wang C, Owsianik G, Janssens A, Voets T, Zhu MX: Regulation of the $\mathrm{Ca}^{2+}$ sensitivity of the nonselective cation channel TRPM4. J Biol Chem 2005;280: 6423-6433.

49 Wolf FI: TRPM7: channeling the future of cellular magnesium homeostasis? Sci STKE 2004; 233:pe23.

50 Aarts M, Iihara K, Wei WL, Xiong ZG, Arundine M, Cerwinski W, MacDonald JF, Tymianski M: A key role for TRPM7 channels in anoxic neuronal death. Cell 2003;115:863877.

51 Takezawa R, Schmitz C, Demeuse P, Schrenberg AM, Penner R, Fleig A: Receptor-mediated regulation of the TRPM7 channel through its endogenous protein kinase domain. Proc Natl Acad Sci USA 2004;101:6009-6014.

-52 Jiang X, Newell EW, Schlichter LC: Regulation of a TRPM7-like current in rat brain microglia. J Biol Chem 2003;278:42867-42876.

53 Stayner C, Zhou J: Polycystin channels and kidney disease. Trend Pharmacol Sci 2001;22: 543-546.

54 Barr MM, DeModena J, Barr MM, DeModena J, Braun D, Nguyen CQ, Hall DH, Sternberg PW: The Caenorhabditis elegans autosomal dominant polycystic kidney disease gene homologs lov-1 and pkd-2 act in the same pathway. Curr Biol 2001;11:1341-1346.

55 Ong AC: Polycystin expression in the kidney and other tissues: complexity, consensus and controversy. Exp Nephrol 2000;8:208-214.

56 Wilson PD, Geng L, Li X, Burrow CR: The PKD1 gene product, 'polycystin-1,' is a tyrosinephosphorylated protein that colocalizes with $\alpha_{2} \beta_{1}$-integrin in focal clusters in adherent renal epithelia. Lab Invest 1999;79:1311-1323.

57 Li HP, Geng L, Burrow CR, Wilson PD: Identification of phosphorylation sites in the PKD1encoded protein C-terminal domain. Biochem Biophys Res Commun 1999;259:356-363.

-58 Parnell SC, Magenheimer BS, Maser RL, Calvet JP: Identification of the major site of in vitro PKA phosphorylation in the polycystin-1 C-terminal cytosolic domain. Biochem Biophys Res Commun 1999;259:539-543.

59 Geng L, Burrow CR, Li HP, Wilson PD: Modification of the composition of polycystin-1 multiprotein complexes by calcium and tyrosine phosphorylation. Biochim Biophys Acta 2000;1535:21-35.

-60 Roitbak T, Ward CJ, Harris PC, Bacallao R, Ness SA, Wandinger-Ness A: A polycystin-1 multiprotein complex is disrupted in polycystic kidney disease cells. Mol Biol Cell 2004;15: 1334-1346.

61 Cai Y, Anyatonwu G, Okuhara D, Lee KB, Yu Z, Onoe T, Mei CL, Qian Q, Geng L, Wiztgall $\mathrm{R}$, et al: Calcium dependence of polycystin-2 channel activity is modulated by phosphorylation at Ser812. J Biol Chem 2004;279:1998719995.

62 Kottgen M, Benzing T, Simmen T, Tauber R, Buchholz B, Feliciangeli S, Huber TB, Schermer B, Kramer-Zucker A, Hopker K, et al: Trafficking of TRPP2 by PACS proteins represents a novel mechanism of ion channel regulation. EMBO J 2005;24:705-716. 